\title{
Influence of Exercise Prescription on Subjective Well-being and Sleep Quality of Trailing Elderly Females
}

\author{
Zhang Wei-wei ${ }^{1}$, Xia Jun-mei ${ }^{1}$, Yu Ling ${ }^{1 *}$ \\ Department of Physical Exercises of Central South China University, Changsha 410083;
}

\begin{abstract}
The influence of exercise prescription of different sports on the subjective well-being level and sleep quality of elderly females was studied. The results show that the exercise prescription can all improve the subjective well-being and sleep quality of the trailing elderly females. The traditional sports on the improvement of positive emotion and experience are obviously superior to aerobic sports. The exercise prescription of traditional sports and aerobic sports is significantly higher than fitness-walking sports on promotion of sleep quality and sleep efficiency.
\end{abstract}

\section{Introduction}

According to national statistics, in China, there were 249 million people aged 60 and over accounting for 17.9 percent of the total population by the end of 2018 . It is estimated that by 2050 , the number of elderly people in China will reach a peak of 487 million, occupying $34.9 \%$ of the total population. The elderly population in China nowadays has not only the largest base but also the fastest growing speed in the world. As the group that needs the most care and consideration in the whole social population structure, the health and happiness of the elderly has become the focus of society.

EIM(Exercise is medicine) was a campaign raised by American College of Sports Medicine(ACSM) and American Medical Association (AMA), aiming to promote the concept of encouraging doing sports, such as "sports has plenty of benefits for human bodies and the exercise prescription should be made and used properly".

Recent research has demonstrated that scientific exercising not only enhance athletes' physical fitness but also their psychological health level and subjective sense of happiness. This research is trying to combine various theories of exercise prescriptions and formulate different types of prescriptions according to migrant elderly preferences, including the one which helps improve the accompanying elders' subjective well-being and sleep quality, encouraging them to get into nation-wide fitness actively.

\section{Migrant Older}

Since the 1980s, with the implementation and deepening of the reform and opening-up policy, the process of urbanization has been accelerating. Many young teenagers have entered the city from rural countries through studying and working, and settled in cities as a result. On the other hand, the elderly people swarmed into cities because of reuniting with children, helping to do chores and taking care of grandchildren, forming the group of "migrant older". As a consequence of the "twochild policy", the number and percentage of elderly people seem to increase progressively. According to the statistics published by the national health and hygiene committee, Chinese migrant older now nearly 18 million, accounting for $7.2 \%$ of total flowing population and up to $43 \%$ of whom are intensively caring younger generations.

Migrant older face the problem of adapting urban regulations and restructuring social interpersonal relationships after away from the rural life field, whose psychological health conditions deserve to pay attention. Questionnaire results in terms of the Shenzhen City's migrant olders demonstrate that the mental health conditions of the olds are not optimistic. Except being influenced by comparative social-economic status and migrant pressure prominently, social capital is not only beneficial to migrant olders' psychological health but also produce negative influences to some degree.

\section{Research Object and Methods}

\section{1 research object}

Volunteers then were recruited by scientific research among elderly females living in a certain community of Yuelu District, Changsha City. The requirements are as followed:

1. Age range from 50-65 years old, having general activity ability and being capable of insisting exercise for four months without exercising before.

2.The period of living in local beyond one year.

3.Had passed the health examination and did not took medicine within one or two years. No cardiovascular

\footnotetext{
* Corresponding author: yuling327@126.com
} 
disease and major diseases, significant physical disability and joint injury. Mentally and intelligent normal.

4. The experiments were known and the informed consent was signed.

\subsection{Experiment design}

\subsection{1 prescription exercising group}

Based on acknowledging basic health conditions, 102 elderly female were recruited to the object of migrant elderly women experiment. The different projects were selected by personal preferences (as shown in table 1). Controlled group preserved the original living lifestyles. During the researching process, only 80 volunteers remained after all the experiments completed due to moving (to another district or hometown), falling ill, injury and quitting. Significant differences have not existed in age groups.

Table 1 Researching object grouping

\begin{tabular}{cccc}
\hline & $\begin{array}{c}\text { Beginning } \\
\text { number }\end{array}$ & $\begin{array}{c}\text { Personnel } \\
\text { flowing }\end{array}$ & $\begin{array}{c}\text { Finishing } \\
\text { number }\end{array}$ \\
\hline Aerobics & 37 & $\begin{array}{c}\text { moving (to } \\
\text { another } \\
\text { district or }\end{array}$ & 28 \\
$\begin{array}{c}\text { Traditional } \\
\text { sports }\end{array}$ & 25 & $\begin{array}{c}\text { hometown), } \\
\text { falling ill, } \\
\text { injury and } \\
\text { quitting }\end{array}$ & 12 \\
$\begin{array}{c}\text { Fitness } \\
\text { walking }\end{array}$ & 17 & 19 \\
$\begin{array}{c}\text { sports } \\
\text { Controlled } \\
\text { group }\end{array}$ & 23 & & \\
\hline
\end{tabular}

\subsection{2 prescription exercising scheme}

According to the mental health conditions of migrant female olds, designing prescriptions concerning American College of Sports Medicine (ACSM)' $\mathrm{s}$ exercising scheme and designing regulations and methods, including aerobics sports prescriptions, traditional sports prescriptions, fitness walking sports prescriptions.

Exercising species for women in the experimental group covered aerobics, Five-Animal Exercise and Eight Trig rams Boxing and fitness-walking taught by experts.As what been planned, sports prescriptions are implemented for 16 weeks in exercising station from 9 a.m. to $10 \mathrm{a} . \mathrm{m}$. every morning. Using Polar heart rate telemetering equipment monitored the average heart rates' fluctuation range when objects exercised, and collected data by RPE immediately after finishing tasks.

\subsection{Texting index}

\subsubsection{Subjective well-being}

Table 2 Pre-experiment comparison between experimental group and controlled group $\left(\bar{X}_{ \pm \mathrm{S}}\right)$

\begin{tabular}{lcccc}
\hline & $\begin{array}{c}\text { Controlled } \\
\text { group }\end{array}$ & Aerobics & $\begin{array}{c}\text { Traditional } \\
\text { sports }\end{array}$ & $\begin{array}{c}\text { Fitness- } \\
\text { walking }\end{array}$ \\
\hline Positive affect & $6.53 \pm 1.26$ & $6.11 \pm 1.73$ & $6.14 \pm 1.35$ & $6.17 \pm 1.59$ \\
\hline
\end{tabular}

The authors texted the olds subjective happiness with revised Chinese version Memorial University of Newfound-land Scale of Happiness ( MUNSH ), compiled by Kozma. This scale is made up of 24 projects, structurally classified into four positive affect, negative affect, positive experience and negative experience. To avoid minus figure, the final number would be added 24 and the number range is from 0 to 48 . As a result of this, the higher scores the older got, the higher level of the subjective happiness is. The internal consistency coefficient of the scale is $0.800 \sim 0.859$, and the test-retest reliability correlation coefficient is 0.758 .

\subsubsection{Sleep Quality}

Pittsburgh sleep quality index (PSQI) was adopted during the tests, which consist of 19 self-evaluation and 5 preceptor-evaluation items. 18 of these items composed of sleep quality, sleep latency, sleep duration, sleep efficiency, sleep disorders, sedatives, daytime dysfunction, etc. Scoring $0 \sim 3$ for each and the total score range is $0 \sim 21$, the higher score examiners got the poorer sleep quality they have. Reliability is between $0.65-0.84$ and validity is more than 0.85 .

Scale investigated by normative instruction, which would be explained one by one by investigators. The signatures are not required. As for the elderly female with a low culture degree, the questions would be asked by researchers, answered by themselves and filled in the forms by their offspring.

\subsection{Mathematical Statistics}

All the data would be processed and analyzed statistically by SPSS19 computer program. Statistical methods such as statistical description, t-test would be adopted to process data.

\section{Results and Analysis}

\subsection{Prescription Exercises Influences to migrant olders}

\subsection{1 subjective well-being before homogeneity test}

As table 2 showed,there was little difference between the experimental group and the controlled group before experiments. This indicated that the subjective happiness of elderly women in the two groups was identical so that it could be inferred that experiments are responsible for significant changes in afterward results. 


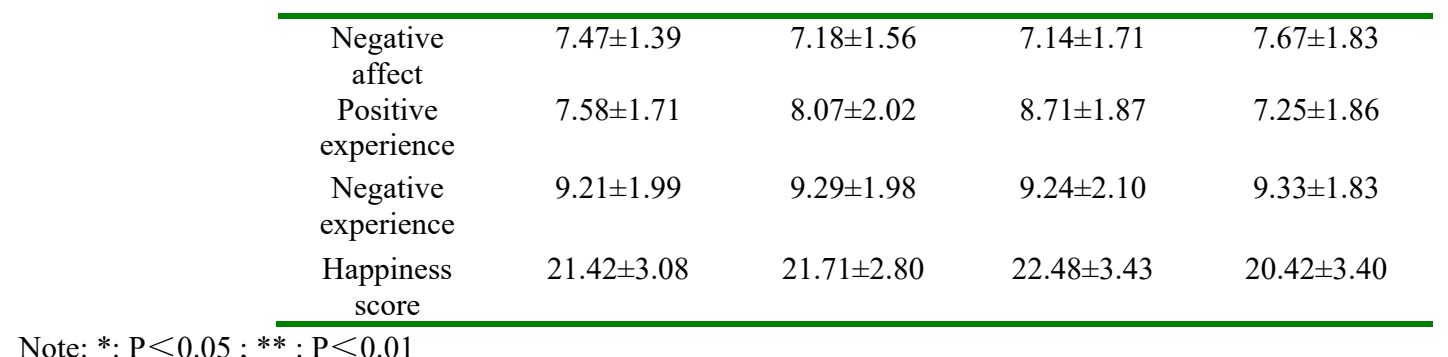

\subsection{2 comparison of the experimental group and controlled group's subjective well-being after prescription exercise}

Compared with pre-experiment, aerobics, traditional sports and fitness-walking are all capable to improve migrant older's subjective wellbeing. While aerobics were shown effective on negative affect and experience and happiness score, traditional sports were influenceable on all items, yet fitness-walking was helpful on negative affects and experience.

T-test independently three types of differences, which are experimental and controlled groups prescription exercise on subjective wellbeing between pre-experiment and afterward. The statistical results show that while traditional sports are effective on positive affect, aerobics and fitness-walking are influenceable on negative experience, yet all three prescription exercise are helpful to the total score of happiness.

According to the variance analysis of three groups, subjective well-being resulted from prescription exercise, multiple comparisons were made with prescription exercises' methods as independent variable and subjective happiness index's variable quantity as the dependent variable. The results showed that traditional sports groups' increased range was much wider than that of aerobics fitness-walking on the positive affect $(\mathrm{P}<0.05)$. While aerobics and traditional walking's decreased range was much lower than fitness-walking group on negative affect $(\mathrm{P}<0.05)$, the trend demonstrate an opposite side as for positive experience and negative experience with traditional sports and aerobics group reached maximum figure respectively $(\mathrm{P}<0.05)$, yet both aerobics and traditional sporting have better performance on the total score on wellbeing compared with fitness-walking group $(\mathrm{P}<0.05)$.

Table3 Comparisons of experimental and controlled groups' subjective wellbeing after experiments $\left(\bar{X}_{ \pm \mathrm{S}}\right)$

\begin{tabular}{|c|c|c|c|c|}
\hline & $\begin{array}{l}\text { Controlled } \\
\text { group }\end{array}$ & Aerobics & Traditional sports & Fitness-walking \\
\hline Positive affect & $6.47 \pm 1.65$ & $6.54 \pm 1.20$ & $7.48 \pm 1.40^{* *}$ & $6.42 \pm 1.56$ \\
\hline $\begin{array}{l}\text { Negative } \\
\text { affect }\end{array}$ & $7.11 \pm 1.88$ & $6.21 \pm 1.55^{* *}$ & $6.57 \pm 1.57 * *$ & $7.67 \pm 1.56^{* *}$ \\
\hline $\begin{array}{l}\text { Positive } \\
\text { experience }\end{array}$ & $7.84 \pm 1.54$ & $8.36 \pm 1.91$ & $10.0 \pm 1.61$ & $7.67 \pm 1.61$ \\
\hline $\begin{array}{l}\text { Negative } \\
\text { experience }\end{array}$ & $9.00 \pm 1.94$ & $7.39 \pm 2.25^{* *}$ & $8.52 \pm 1.78^{* *}$ & $9.25 \pm 2.30 * *$ \\
\hline $\begin{array}{l}\text { Happiness } \\
\text { score }\end{array}$ & $22.21 \pm 3.31$ & $\begin{array}{c}25.29 \pm 4.04 * \\
*\end{array}$ & $26.38 \pm 3.38 * *$ & $21.17 \pm 3.35^{* *}$ \\
\hline
\end{tabular}

Note:*: $\mathrm{P}<0.05 ; * *: \mathrm{P}<0.01$

As a significant comprehensive psychological index to measure psychological health and living quality, it not only includes life satisfaction, self-actualization, pleasure and tranquility, but also owns the appearance of positive emotions and disappearance of negative emotions. To support their young generation, migrant elderly female move from hometown to the residential urban, whose living environment has changed and lack of sense of belonging. Adjustment on their living lifestyles easily leads to loneliness, anxiety and social intercourse disorders, effecting their subjective wellbeing level.

The results indicate that prescription exercise like fitness-walking and traditional sports such as aerobics, Five-Animal Exercise, and Eight Trigrams Boxing are helpful to raise migrant elderly female's subjective happiness level. This means that prescription exercise is beneficial to regulate their emotions, improve the interpersonal relationship and enhance psychological health, which is helpful to form and promote subjective well-being. Besides, the research also confirms that different prescription exercise has different effects on migrant elderly female's subjective happiness. Take traditional sports, for example, taking part in traditional exercise brought much more positive affect and experience than that of aerobics, which corresponds with Tao Guan's scientific results. This may because traditional sports' movement structure is comparatively complicated and has special requirements on movements, thought and respiration. Having experienced the fusion process of movements, respiration and thoughts offer more successful experiences for them, which produces more positive emotions and improve subjective wellbeing level.

\section{2 the influence to migrant elderly female's sleep quality from prescription exercise}

\subsection{1 homogeneity detection of sleep quality before experiments}


According to table 4, 4 groups of migrant elderly female sleep quality pre-experiments results were analyzed by One-Way ANOVA, including aerobics, traditional sports, fitness-walking, and controlled groups, to investigate whether these female's sleep quality is on the same level or not. The results show that all the indexes including sleep quality, sleep latency, sleep duration, sleep efficiency, sleep disorders, sedatives, daytime dysfunction, and total score have no significant differences, which means that sleeping quality of the experimental group is consistent with that of controlled group.

Table 4 Comparison of experimental and controlled groups' PSQI before experiments $\left(\bar{X}_{ \pm \mathrm{S}}\right)$

\begin{tabular}{lllll}
\hline Sleep quality & $1.26 \pm 0.73$ & $1.25 \pm 0.82$ & $1.19 \pm 0.87$ & $1.33 \pm 0.78$ \\
Sleep latency & $1.58 \pm 0.77$ & $1.59 \pm 0.82$ & $1.62 \pm 0.92$ & $1.58 \pm 0.67$ \\
Sleep duration & $1.32 \pm 1.06$ & $1.50 \pm 0.99$ & $1.38 \pm 1.07$ & $1.75 \pm 0.97$ \\
Sleep efficiency & $1.05 \pm 0.78$ & $1.43 \pm 0.90$ & $1.29 \pm 0.96$ & $1.50 \pm 0.80$ \\
Sleep disorders & $1.47 \pm 0.90$ & $1.64 \pm 0.95$ & $1.43 \pm 0.98$ & $1.83 \pm 0.83$ \\
Sedatives & $0.58 \pm 0.69$ & $0.68 \pm 0.72$ & $0.62 \pm 0.74$ & $0.67 \pm 0.78$ \\
Daytime dysfunction & $1.26 \pm 0.81$ & $1.57 \pm 0.87$ & $1.52 \pm 0.93$ & $1.42 \pm 0.79$ \\
Total score & $8.53 \pm 3.09$ & $9.71 \pm 3.27$ & $9.05 \pm 3.65$ & $10.08 \pm 3.06$ \\
\hline
\end{tabular}

Note : *: $\mathrm{P}<0.05 ; * *: \mathrm{P}<0.01$

\subsection{2 comparison of migrant sleep quality after prescription exercise}

Compared with pre-experiments, the figure of aerobics was adjusted on sleep quality, sleep disorders, and total score. Traditional sports numbers were also changed in terms of sleep quality, sleep latency, sleep efficiency, sleep disorders and total score, while that of fitnesswalking only varied on sleep latency, sleep duration, sleep disorders, and total score.

Independent Samples T-Test was carried out on the difference between the post-test and pre-test value of sleep quality (including the experimental and controlled group of all three groups respectively of migrant elderly female), while prescription exercise's influences on these objects' sleep quality were analyzed at the same time.
Statistical results indicate that traditional sports are positively influential on sleep quality, while both traditional sports and aerobics are differed from former in sleep latency, yet traditional sports also works on sleep efficiency and all three kinds of prescription exercise are different compared to the past.

According to the variance analysis of three kinds of prescription exercise groups on sleep quality, multiple comparisons were made with prescription exercises' methods as independent variable and sleep quality index as the dependent variable. The results showed that on the aspect of sleep quality, sleep latency, sleep duration, sleep efficiency and sleep disorders, traditional sports and aerobics' descent are much higher than that of fitnesswalking $(\mathrm{P}<0.05)$, with the largest decline on traditional sports' figure.

Table 5 Comparison of experimental and controlled groups' PSQI

\begin{tabular}{lllll}
\hline & $\begin{array}{l}\text { Controlled } \\
\text { group }\end{array}$ & Aerobics & $\begin{array}{l}\text { Traditional } \\
\text { sports }\end{array}$ & $\begin{array}{l}\text { Fitness- } \\
\text { walking }\end{array}$ \\
\cline { 2 - 5 } Sleep quality & $1.21 \pm 0.63$ & $1.05 \pm 0.70^{* *}$ & $0.76 \pm 0.70^{* *}$ & $0.75 \pm 0.62$ \\
Sleep latency & $1.63 \pm 0.60$ & $1.21 \pm 0.79$ & $0.76 \pm 0.69^{* *}$ & $0.83 \pm 0.58^{* *}$ \\
,Sleep duration & $1.32 \pm 0.48$ & $1.07 \pm 0.77$ & $0.90 \pm 0.70$ & $1.08 \pm 0.67^{* *}$ \\
Sleep efficiency & $0.95 \pm 0.62$ & $1.25 \pm 0.84^{* *}$ & $0.62 \pm 0.67^{* *}$ & $0.83 \pm 0.72$ \\
Sleep disorders & $1.42 \pm 0.77$ & $1.18 \pm 0.90^{* *}$ & $0.57 \pm 0.68^{* *}$ & $0.75 \pm 0.87^{* *}$ \\
Sedatives & $0.53 \pm 0.70$ & $0.50 \pm 0.58$ & $0.38 \pm 0.50$ & $0.42 \pm 0.51$ \\
Daytime & $1.05 \pm 0.71$ & $1.00 \pm 0.72$ & $1.10 \pm 0.70$ & $1.00 \pm 0.74$ \\
dysfunction & & & & \\
Total score & $8.11 \pm 1.45$ & $6.39 \pm 2.63 * *$ & $5.76 \pm 2.77^{* *}$ & $6.08 \pm 1.67^{* *}$ \\
\hline
\end{tabular}

Note : *: $\mathrm{P}<0.05 ; * *: \mathrm{P}<0.01$

Regular sleep duration and rhythm has something to do with individual physical and psychological health, which is also a significant symbol of personal somatopsychic health. For migrant elderly female, they have been through not only the decline of metabolism level with age growth and multi-organ failure, but also the changing environment. This usually leads to anxiety, depression and insomnia, which is harmful to their physical and mental health. Physical exercise can improve sleep quality so that mental state could be improved, sleep quality and duration are also significantly increased to reduce the interference in the sleep process. Exercise may play a role in improving sleep quality through a two-way regulatory pathway of excitation and inhibition of the central nervous biological clock.In conclusion, the results show that the exercise prescription of traditional sports such as Five-Animal Exercise and Eight Trigrams Boxing, the exercise prescription of aerobic sports such as square dance and aerobics, and the exercise prescription of fitness-walking sports such as fitness walking and jogging, can all improve the subjective well-being and sleep quality of the migrant elderly females, especially for sleep quality, sleep latency and sleep disorders.

\section{Conclusions}

The exercise prescription can all improve migrant elderly females' subjective well-being and sleep quality. The 
prescription traditional sports on the improvement of positive emotion and experience are superior to that of aerobic sports.Traditional sports and aerobic sports are significantly higher than fitness-walking sports on promotion of sleep quality and sleep efficiency.

\section{Acknowledgement}

The authors appreciate all the comments provided on this Article, including those from Minfang Li, Hongyin Bi, Schmutte, Davidson, Dirks-Naylor, Hansen, Dendale, Nishiyama, etc.

\section{References:}

1. Schmutte T, Davidson L,O'connell M. Improved sleep, diet, and exercise in adults with serious mental illness: results from a pilot self-management intervention.Psychiatr Q 11(2017)

2. Dirks-Naylor A J, Griffiths C L, Gibson J L, et al. The prevalence of exercise prescription-related course offering in United States pharmacy school curricula: Exercise is medicine. Adv Physiol Educ, 322(2016)

3. Hansen D, Dendale P, Coninx K, et al. The European Association of Preventive Cardiology Exercise Prescription in Everyday Practice and Rehabilitative Training (EXPERT) tool: A digital training and decision support system for optimized exercise prescription in cardiovascular disease. Concept, definitions and construction methodology. Eur J Prev Cardiol,1031(2017)

4. Nishiyama T, Mizuno T, Kojima M, et al. Criterion validity of the Pittsburgh Sleep Quality Index and Epworth Sleepiness Scale for the diagnosis of sleep disorders.Sleep Med, 429(2014)

5. Chi I, Jordan-Marsh M, Guo M, et al. Tai Chi reduction of depressive symptoms for order adults: A meta-analysis of randomized trials $[\mathrm{J}]$. Geriatrics \& Gerontology International, 12(2013)

6. Li F, Fisher K J, Harmer P, et al. Tai Chi and SelfRated Quality of Sleep and Daytime Sleepiness in Older Adults: A Randomized Controlled Trial[J]. Journal of the American Geriatrics Society,900(2004) 